\title{
Mersilene mesh brow suspension: efficiency and complications
}

\author{
C R Hintschich, M Zürcher, J R O Collin
}

\begin{abstract}
The use of the Mersilene mesh sling brow suspension procedure for the correction of severe blepharoptosis in 76 lids of 54 patients is presented. After a median follow up of 20 months functional and cosmetic results and complications were evaluated. The method is considered to be an alternative for those cases not primarily suitable for autogenous fascia lata brow suspension.
\end{abstract}

(Br ₹ Ophthalmol 1995; 79: 358-361)

Brow suspension is considered to be the most efficient method for the surgical management of severe blepharoptosis associated with poor levator function. The method, also known as frontalis suspension or sling, ${ }^{1-3}$ was first described by Payr. ${ }^{4}$ The transmission of frontalis muscle activity to the upper lid is achieved by the insertion of a biologically acceptable non-stretchable rod-shaped connection between the two. Different techniques $^{2} 35-9$ and a variety of materials ${ }^{10-16}$ have been used.

The synthetic non-absorbable macro-mesh material Mersilene for ptosis surgery was first described by Downes and Collin in 1989. ${ }^{17}$ As the results were very encouraging and the technique is relatively simple, the use of this method was continued. This survey analyses the further functional and cosmetic outcome and complications of Mersilene mesh brow suspensions (MMBS) performed at the Moorfields Eye Hospital from 1988 to 1992.

\section{Materials and methods}

Mersilene mesh for brow suspension has been used in 76 ptotic eyelids of 54 patients. Thirty three patients (44 lids) were children, 27 of them under the age of 3 years (average $1 \cdot 5$ ), and six between 3 and 6 (average 3.7). There was one adolescent (age 14) and 20 adults (age range 25 to 88 , average 59). All patients had severe unilateral (25 patients) or bilateral (29 patients) ptosis with a levator function of 0 to $5 \mathrm{~mm}$ (average $2.4 \mathrm{~mm}$ ). The aetiology of the blepharoptosis in the children's group was congenital ptosis in 25 patients, blepharophimosis syndrome in five, congenital third nerve palsy in two, trigemino-oculomotor synkinesis (Marcus-Gunn phenomenon) in one, and cyclic ocular motor palsy in one child. In the adults the diagnosis was chronic progressive external ophthalmoplegia (CPEO) in nine, congenital ptosis in four, oculopharyngeal dystrophy in three; and congenital and acquired third nerve palsy, post-traumatic ptosis, and myotonic dystrophy in one case each.

Seven patients had undergone previous ptosis surgery.

The surgical technique has been described previously ${ }^{2}$ using a modified Fox's pentagon. ${ }^{3}$ Stab incisions are made in the eyelid and eyebrow. The lid incisions are positioned 3-7 mm from the eyelid margin to match the contralateral skin crease in an attempt to reach symmetry, at the junctions between the medial and central and central and lateral thirds of the eyelid. The incisions are made through skin and orbicularis muscle to the tarsal plate, and they are small. Two brow incisions are made within the superior hairline of the eyebrow, just above the position of the medial and lateral canthus. The fifth incision is made midway between these incisions, $7-10 \mathrm{~mm}$ above the brow. Preoperatively the sling is cut along the non-stretchable long access of a sheet of Mersilene mesh $150 \mathrm{~mm}$ long and 5-8 mm wide. It is packed and autoclaved. Before use it is soaked in an antibiotic solution.

The sling is inserted using a Wright's fascia needle in a suborbicularis muscle plane. Pieces of 4.0 silk suture are inserted temporarily in the lid and brow incisions. They make it easier to adjust the lid contour and height. When the desired lid height is attained by pulling on both ends of the sling, the silk sutures are pulled out and a single knot in the forehead is made under tension. It is secured with a 5.0 Ethibond suture. Excess material is trimmed, the sling is allowed to retract into the tissues of the forehead. It is essential to bury the knot with subcutaneous sutures $(6.0$ Vicryl), preventing exposure of the material. The skin is closed with 6.0 nylon. A traction suture is placed in the lower lid and a pressure dressing left for 2 days.

A systemic antibiotic was given intraoperatively in all but 13 cases. Oral broad spectrum antibiotics were prescribed for 1 week postoperatively. Topical antibiotics and lubricants were routinely used for the first week and then as required.

The patients were operated by different surgeons.

\section{Results}

Two groups of patients were assessed and differentiated by their follow up times. Group A consisted of 10 operated lids with a short term follow up of 1-6 months (average 4 months). Group B consisted of 66 lids with a longer term follow up of more than 6 months (average 23 months). The average follow up of all 76 cases was 20 months, ranging from 1 to 48 months. 
The functional and cosmetic results were assessed separately. There were three levels of function: 'good', 'moderate', and 'poor'. For the assessment of cosmesis 'excellent' was an additional level. The functional assessment depended mainly on whether the pupillary axis was clear ('good' and 'moderate'). If there were minor problems like mild exposure or changing height it was assessed as 'moderate'. The cosmetic result depended on the subjective estimation of the examiner and the patient or his parents. A moderate result was mainly due to asymmetry in unilateral operated cases, but also to lash ptosis or lateral droop.

\section{GROUP A}

In all cases a significant improvement in lid height was achieved. The improvement, as assessed by preoperative and postoperative vertical palpebral aperture measurements, ranged from 1 to $4 \mathrm{~mm}$ and averaged $2.8 \mathrm{~mm}$. In the short follow up period of mean 4 months, the lid maintained at least its initial position. Functionally seven lids showed a good and three a moderate result. The cosmetic assessment showed three excellent, five good, and two moderate results.

There were no complications in any of these short term follow ups, no mesh extrusions, and nobody needed a second operation.

\section{GROUP B}

All but two lids were well elevated in the immediate postoperative period with an improvement in the vertical palpebral aperture ranging from 1 to $8 \mathrm{~mm}$ (mean $2.9 \mathrm{~mm}$ ). The two failures were due to insufficient surgery. The lid position during the follow up period was stable in 60 lids, but six lids developed a recurrence, either spontaneously (three lids) or after a complication (three lids). If there was a spontaneous droop, it occurred during the first 6 postoperative months.

Functionally 52 lids showed a good, 11 a moderate, and three a poor result. The cosmetic outcome was excellent in 19 , good in 20 , moderate in 23, and poor in four cases.

\section{COMPLICATIONS}

Eight patients developed a granuloma with or without an extrusion of the knot. More details are presented in the case reports.

In 12 lids, 11 of them in children, further surgery was needed at a later date for functional or cosmetic improvement. The reason for this further surgery in the children's group was cosmesis in six lids, impaired function in three lids (two due to insufficient surgical results, one to recurrence), and two as a consequence of granuloma formation and sling removal. In all cases the patients underwent autogenous fascia lata brow suspension procedure (AFLBS). One adult had to be reoperated owing to a surgical failure and a redo MMBS was performed.

There was no case of significant exposure problem and no lid lowering had to be performed.

\section{Case reports}

\section{CASE 1 (MA)}

A 49-year-old man with bilateral ptosis due to ocular myopathy underwent an unilateral Mersilene mesh brow suspension (MMBS) to his right eye. Postoperatively the functional result was good. There was no perioperative antibiotic prophylaxis. Two months postoperatively the patient had trauma to his right forehead. A large haematoma developed and a big lump remained. Ten months postoperatively a granuloma developed. One year later the granuloma and part of the sling were excised. The functional result was not impaired and no further surgery is planned.

\section{CASE 2 (JB)}

A 68-year-old man with the diagnosis of a CPEO and a recurrence of bilateral ptosis after bilateral ALR underwent a right MMBS. Perioperative antibiotics were given. The functional result was good, but he needed some lubricants owing to a poor Bell's phenomenon. One month postoperatively he developed an extrusion of the Mersilene knot in his forehead. An excision was performed 4 months postoperatively. A second extrusion was seen 2 months later, which was excised. Eighteen months later the forehead was still quiet, the functional outcome with a clear pupillary axis and complete voluntarily closure was good.

\section{CASE 3 (SD)}

A 76-year-old man with a CPEO developed a small abscess in one eyelid incision 1 month after a successful MMBS to his right eye. The abscess was treated conservatively with antibiotics and resolved completely. Then he underwent a MMBS to his left eye without antibiotic prophylaxis. Postoperatively the lid came up from 3 to $6 \mathrm{~mm}$. Two weeks postoperatively a local infection was noticed, which was treated conservatively. Five months postoperatively the sling was removed. The skin abscess healed completely, but there was a decrease of the lid height of 1 to $2 \mathrm{~mm}$. The function was still good; no further surgery is planned.

\section{CASE 4 (MF)}

A 2-year-old child with left congenital ptosis and a previous history of unsuccessful levator resection underwent MMBS. Antibiotic prophylaxis was given, the postoperatively result was excellent with a palpebral aperture coming up to $8 \mathrm{~mm}$ from $2 \mathrm{~mm}$ preoperatively. Five months later a granuloma developed spontaneously in the lateral part of the upper lid. After conservative treatment the sling had to be removed 6 months later. The functional and cosmetic outcome is not satisfactory, a left AFLBS is planned. 
CASE 5 (RH)

A boy with the blepharophimosis syndrome had already undergone a bilateral brow suspension procedure (BSP) with synthetic material for severe ptosis at the age of 3 months. Because of a poor result on the left eye an MMBS was performed at the age of 2 years. One month postoperatively a granuloma in the upper lid developed, which was removed elsewhere. As the granuloma recurred, it was totally excised and the sling removed 5 months postoperatively. The ptosis recurred, and a bilateral AFLBS was performed later.

CASE 6 (JS)

A 65-year-old women with an oculopharygeal dystrophy underwent a bilateral MMBS without antibiotic prophylaxis. Postoperatively both lids came up, the cosmetic and functional result was good. Four months postoperatively she had developed a protrusion of the knot in her forehead, which had to be excised. A month later the forehead was well healed, there were no further complications. The lid stayed in position, and the outcome 3 months later was still good.

CASE 7 (ST)

A 70-year-old women with oculopharyngeal dystrophy, who had undergone unsuccessful BSP with stored fascia lata 2 years earlier, had a bilateral MMBS. Antibiotics were given perioperatively. Her right lid came up nicely, her left lid still stayed undercorrected postoperatively. She developed an extrusion of the knot in her left forehead. Six months postoperatively the Mersilene sling was tightened and the knot buried. The result was good and the palpebral apertures came up to $8 \mathrm{~mm}$ on the right and $7 \mathrm{~mm}$ on the left compared with 3 and $4 \mathrm{~mm}$ preoperatively with a follow up of 19 months.

CASE 8 (JE)

A little girl with a congenital right ptosis and hypotropia underwent a combined unilateral Knapp procedure and an MMBS. Perioperatively antibiotics were given. Postoperatively the pupil was clear, the palpebral aperture was variable. One year later a granuloma in the upper fornix developed and the lid dropped. The granuloma was excised and a MMBS redo operation performed. Four months later discharge and bleeding were noticed. This condition settled down, but another year later there were two small nodules at the upper edge of the tarsal plate with no obvious granuloma. The palpebral aperture was still variable. The cosmetic result was moderate but satisfactory. The patient's parents did not want further surgery.

\section{Discussion}

In infancy and early childhood ptosis surgery is primarily undertaken for the prevention of deprivation amblyopia. ${ }^{18} 19$ This is a functional indication and often a matter of some urgency. In adulthood surgery rarely is urgent and the indications can be functional or cosmetic. There is no doubt that brow suspension procedures are necessary to achieve satisfactory correction of severe blepharoptosis associated with minimal levator function. While general agreement exists regarding the indications for brow suspension surgery, there is no such common consensus for the suspensory material used. As many studies have shown, autogenous fascia lata is regarded as the best material for brow suspension procedures. ${ }^{9} 1220-22$ but, as has been emphasised before, ${ }^{23}$ this method has some disadvantages as well. General anaesthesia is necessary for fascial harvesting, the leg needs to be of a certain size, and the technique is time consuming and not without risk. Many alternative materials have been used for brow suspension and these can be subdivided into biological and synthetic materials. The first group includes preserved human fascia, ${ }^{16}$ sclera, ${ }^{11}$ bovine fascia, ${ }^{13}$ skin, ${ }^{24}$ and muscle, ${ }^{25} 26$ the latter metal implants, ${ }^{26}$ silicone rods, ${ }^{814}$ Gore-tex bands, ${ }^{27}$ and different sutures like silk, Supramid, polyester, and Mersilene. ${ }^{15} 2829$

The idea of using Mersilene mesh for a brow suspension procedure was to avoid the disadvantages of fascial harvesting and to find a material which would be integrated into the host tissue. Mersilene mesh acts as a permanent scaffold which supports significant fibrovascular ingrowth. ${ }^{30-32}$ A permanent tissue fixation should promise excellent function with low recurrence rates and should minimise extrusion. ${ }^{23}$ The first results obtained with Mersilene mesh were very encouraging ${ }^{1723}$ and the longer term results support this promise. In this series the functional outcome was good with only three cases of all 76 operated lids $(4 \%)$ being assessed as poor, the remaining $96 \%$ were good or moderate. The cosmetic results were very similar with only four of 76 eyes showing a poor result, the remaining $95 \%$ were excellent, good, or moderate.

There were six cases of recurrence of ptosis in the group B (follow up more than 6 months). Three of these were secondary to a complication. The remaining three occurred spontaneously in the first 6 postoperative months. There was no recurrence after this period. Since all recurrences occurred early, one might add both groups $\mathrm{A}$ and $\mathrm{B}$. This would give a total recurrence rate of $8 \%$ including $4 \%$ of spontaneous failures.

Twelve lids $(15 \cdot 7 \%)$ need further surgery for either functional (six lids) or cosmetic (six lids) reasons.

Nine out of 66 operated lids $(13.6 \%)$ of group B (follow up more than 6 months) had complications - infection, granuloma, or extrusion. These complications occurred mainly in the first postoperative months (seven cases), with only two after 10 to 12 months. One of these (case 1) obviously is causally related to trauma. There were no complications in group A. The complication rate of all 
operated lids is $11.8 \%$. It is interesting that there was no complication in any of the 20 lids operated after January 1991. Since extrusions in the forehead have been seen, the technique of closing the sling and the forehead wound has been modified. The knot is now smaller, and a meticulous closure of the subcutaneous tissue layer is performed. This probably has reduced the number of early extrusions since 1991. Perioperative antibiotic prophylaxis does not seem to prevent a granuloma formation.

Although the results of this larger number of Mersilene mesh brow suspension procedures are not quite as good as in the two previous studies, ${ }^{1723}$ the numbers still compare well with alternative non-autogenous suspensory materials. ${ }^{11} 15163334$ The low recurrence rate seems to support the concept of a maximal tissue ingrowth. Even if a complication occurs and a granuloma has to be excised, the lid height and contour are maintained in the majority of cases. The number of extrusions on the other hand once again shows that the implantation of any foreign material will always give the risk of such a complication. It is a natural reaction of a biological system and every effort should be made to minimise these complications.

The Mersilene mesh sling brow suspension procedure is considered to be an adequate alternative method for those cases of severe ptosis, which are not primarily suitable for autogenous fascia lata brow suspension. Autogenous fascia still remains the preferred material. However, a large number of patients have been prevented from developing amblyopia by Mersilene mesh brow suspension and many of these will not need any more surgery. A definite evaluation of this method cannot yet be given but our results continue to be promising. Further follow ups will show whether the method will stand the test of time and find a definitive place in the management of severe blepharoptosis.

1 Mustardé JC. Repair and reconstruction in the orbital region. 2nd ed. Edinburgh: Churchill Livingstone, 1980: 325-8.

2 Beard C. Ptosis. 2nd ed. St Louis: Mosby, 1976: 164-9.

3 Fox SA. Congenital ptosis. II Frontalis sling. $\mathcal{f}$ Paediatr Ophthalmol 1966; 3: 25-8.

4 Payr E. Plastik mittels freier Faszientransplantation bei Ptosis. Dtsch Med Wochenschr 1909; 35: 822.

5 Wright WW. The use of living sutures in the treatment of ptosis. Arch Ophthalmol 1922; 51: 99-102.
6 Crawford JS. Repair of ptosis using frontalis muscle and fascia lata. Trans Am Acad Ophthalmol 1956; 60: 672-8.

7 Fox SA. Complications of frontalis sling surgery. $A m \mathcal{F}$ Ophthalmol 1967; 63: 758-62.

8 Goldberger S, Conn H, Lemor M. Double rhomboid silicone rod frontalis suspension. Ophthal Plast Reconstr Surg 1991; 7: 48-53.

9 Collin JRO. A manual of systemic eyelid surgery. 2nd ed. Edinburgh: Churchill Livingstone, 1989: 61-5.

10 Crawford JS. Fascia lata: its nature and fate after implantation and its use in ophthalmic surgery. Trans Am Ophthalmol Soc 1968; 66: 673-745.

11 Bodian M. Repair of ptosis using human sclera. Am $\mathfrak{f}$ Ophthalmol 1968; 65: 352-8.

12 Beyer CK, Albert DM. The use and fate of fascia lata and sclera in ophthalmic plastic and reconstructive surgery. The 1980 Wendell Hughes Lecture. Ophthalmology 1981; 88: 869-96.

13 Billet E. Bovine fascia lata in ptosis surgery. $\mathrm{Am} \mathfrak{f}$ Ophthalmol 1968; 65: 561-71.

14 Tillet $\mathrm{CW}$, Tillet GM. Silicone sling in the correction of ptosis. Am F Ophthalmol 1966; 62: 521.

15 Katowitz JA. Frontalis suspension in congenital ptosis using a polyfilament, cable-type suture. Arch Ophthalmol 1979; 97: 1659-63.

16 Broughton WL, Matthews II JG, Harris DJ. Results of treatment using lyophilized fascia lata for frontalis suspensions. Ophthalmology 1982; 89: 1261-6.

17 Downes RN, Collin JRO. The mersilene mesh sling - a new concept in ptosis surgery. Br $\mathcal{F}$ Ophthalmol 1989; 73: 498-501.

18 Harrad RA, Graham CM, Collin JRO. Amblyopia and strabismus in congenital ptosis. Eye 1988; 2: 625-7.

19 Beaconsfield M, Walker JW, Collin JRO. Visual development in the blepharophimosis syndrome. $\mathrm{Br} \mathcal{F}$ Ophthalmol 1991; 75: 746-8.

20 Wagner RS, Mauriello JA, Nelson LB, Calhoun JH, Flanagan JC, Harley RD. Treatment of congenital ptosis with frontalis suspension: a comparison of suspensory with frontalis suspension: a comparison

21 Crawford JS. Repair of ptosis using frontalis muscle and fascia lata: a 20 year review. Ophthalmic Surg 1977; 8: $31-40$.

22 Kemp EG, James CR, Collin JRO. Brow suspension in the management of ptosis: an analysis of over 100 cases. Trans Ophthalmol Soc UK 1986; 105: 84-7.

23 Downes RN, Collin JRO. The mersilene mesh ptosis sling. Eye 1990; 4: 456-63.

24 Fox SA. A new frontalis skin sling for ptosis. Am $\mathfrak{f}$ Ophthalmol 1968; 65: 359-62.

25 Reese RG. An operation for blepharophimosis with the formation of a fold in the lid. Arch Ophthalmol 1924; 53: 26-30.

26 Duke-Elder S. System of ophthalmology. London: Kimpton, 1974; 13: 543-9.

27 Adenis JP, Lebraud P, Mathon M. Utilisation du PFTE (Goretex) dans la suspension palpebro-frontale pour le ptosis. F Fr Ophtalmol 1987; 10: 607-9.

28 Boergen KP. München 1993 (personal communication).

29 Cole MD, O'Connor GM, Raafai F, Willshaw HE. A new synthetic material for brow suspension procedure. $\mathrm{Br} \mathcal{F}$ Ophthalmol 1989; 73: 35-8.

30 Amis AA. Filamentous implant reconstruction of tendon defects: a comparison carbon and polyester fibres. $\mathcal{f}$ Bone foint Surg 1982; 643: 682 .

31 Adler RH, Fume CN. Use of pliable synthetic mesh in the repair of hernias and tissue defects. Surg Gynecol Obstet 1959; 108: 199-206.

32 Product Sheet - Mersilene mesh, revised 9/85 from Ethicon Ltd.

33 Saunders RA, Grice C. Early correction of severe congenital ptosis. F Pediatr Ophthalmol Strabismus 1991; 28: 271-3.

34 Wilson ME, Johnson RW. Congenital ptosis. Long-term results of treatment using lyophilized fascia lata for frontalis suspension. Ophthalmology 1991; 98: 1234-7. 